\title{
Coco: Relasi Keluarga Hingga Tradisi Budaya
}

\author{
Ghalif P. Sadewa \\ Program Pascasarjana Institut Seni Indonesia Yogyakarta \\ Jalan Suryodiningratan No 8 Yogyakarta 55143 Telp/Fax (0274) 419791 \\ E-mail: ghalifputra@ymail.com
}

\begin{abstract}
Abstrak
Keluarga menjadi hal pokok dan pertama dimana relasi diajarkan. Ajaran moral dan pedoman hidup merupakan bagian eksistensi yang nyata dalam bentuk komunikasi anggota keluarga. Wajar adanya jika tema kasih sayang dalam keluarga kerap dijumpai pada sebuah film. Kedekatan emosi, persoalan yang sama, hingga latar cerita membuat tema ini mudah diterima penontonnya. Konflik sederhana namun jika diramu dengan baik tentu akan memikat penonton. Apalagi jika menyajikan visual yang memukau. Coco adalah perjalanan emosional yang mudah dimengerti. Sebuah perjalanan singkat untuk kembali mengenal arti keluarga dan wisata budaya Meksiko dalam Dia de los Muertos. Coco merajut makna kehilangan dan kematian bukan dengan cara klise. Menyuguhkan hal yang tampak lebih indah dalam memaknai sebuah kematian. Nafas naratif tak sekadar dari dialog dan konflik antar tokohnya jauh dari hal itu, Coco menawarkan elemen visual yang menawan. Musik yang saling mengisi emosional tokoh dengan ujung dramatik adegan yang menguras air mata.
\end{abstract}

Kata kunci: film, relasi keluarga, musik, kematian, budaya Meksiko.

\begin{abstract}
Family becomes the first and most important thing where relationships are taught. Moral teachings and life guidelines are a real part of existence in the form of communication between family members. Thus, it is natural to find a movie theme about love in the family. The closeness of emotions, the same issues, to the background of the story make this theme easily accepted by the audience. Conflict is simple but if mixed well it will certainly attract the audience. Especially if it presents stunning visuals. Coco is an easy-to-understand emotional journey about a return to the family and a cultural trip to the Mexican culture of Dia de los Muertos. Coco weaves the meaning of loss and death not by cliches. It presents things that look more beautiful in interpreting death. Narrative breath is not just from dialogue and conflict between characters. Far from it, Coco offers charming visual elements. The music fills each other's emotional figures with the dramatic edge of a tear-shedding scene.
\end{abstract}

Keywords: film, family relations, music, death, Mexico culture.

\section{Pendahuluan}

Kerja kolektif yang baik dan patut diacungi jempol memang pantas diberikan kepada Pixar Animation Studio dan Walt Disney Pictures. Dari Toy Story Trilogy (1995, 1999, 2010), A Bug's Life (1998), Finding Nemo (2003), Cars (2006), dan Up (2009). Merupakan torehan karya Pixar dan Disney yang melekat pada masyarakat khususnya penikmat film bergenre animasi. Tentu masih banyak lainnya yang sukses dipasaran dan membawa pulang Piala Oscar sebagai bentuk capaian tertinggi dalam ranah industri film dunia. Bukan Pixar pula kalau tidak memanjakan mata penggemarnya dengan karakter tokoh-tokohnya, kedetailan setiap setting, gerakan animasi y ang rapi, audio yang jernih, naratif yang baik, dan tentu cerita yang selalu orisinil.

Kepekaan Pixar dan Disney dalam menyuguhkan hal baru tanpa mengkesampingkan isu sosial dalam masyarakat adalah kunci sukses yang juga nampak pada film terbarunya, Coco (2017). Film animasi dengan durasi 109 menit ini terbukti berhasil membawa dua penghargaan Oscar tahun 2018 dengan kategori Best Animated Feature Film serta Original Song untuk salah satu soundtracksnya, Remember Me. Lewat tangan dinginnya, Lee Unkrich mencatatkan prestasi sebagai sutradara yang meletakkan Coco sebagai film terlaris di Meksiko sepanjang masa, dengan mengantongi 43,1 juta dolar atau 582 miliar rupiah. 


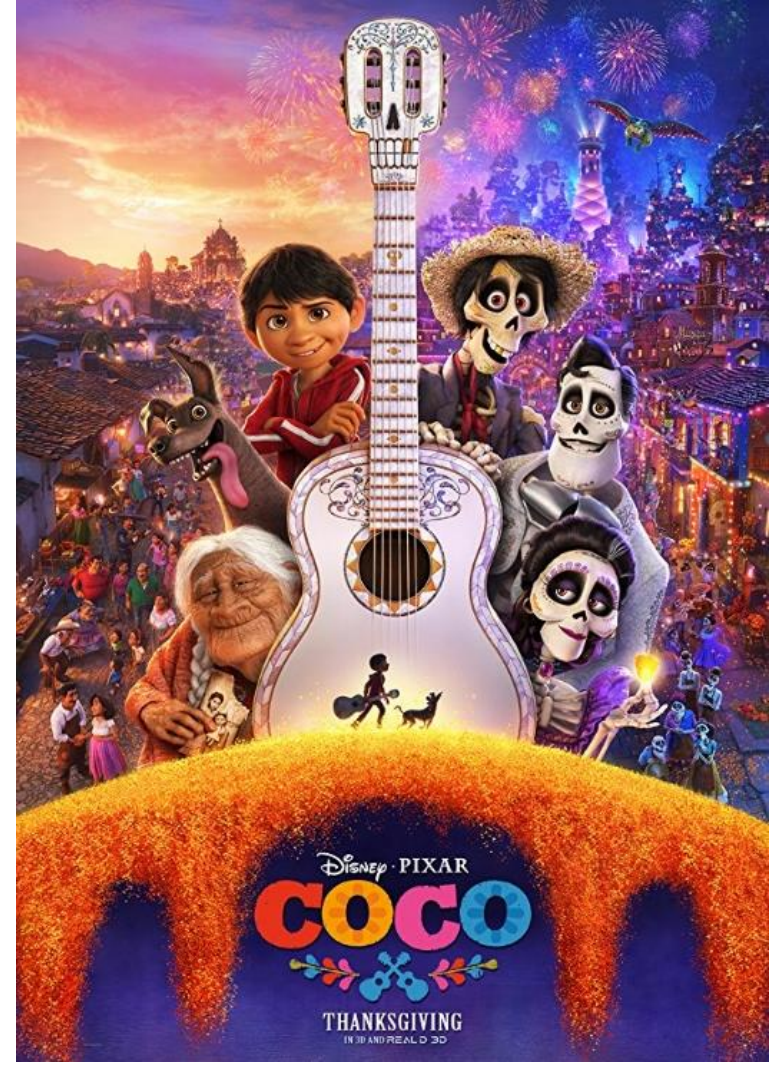

Gambar 1. Poster resmi film Coco (Sumber: Disney. Pixar's "Coco")

Coco bercerita tentang sebuah mimpi dan kebudayaan leluhur. Bagi keluarga Miguel segala hal yang berhubungan dengan musik adalah kutukan. Takdir mereka adalah menjadi pembuat sepatu turun temurun, itu yang mereka yakini. Maka tak heran jika Miguel yang masih berusia 12 tahun bercita-cita menjadi musisi dan mengikuti jejak idolanya, Ernesta de la Cruz ditentang keluarga besarnya, bahkan sampai leluhurnya. Jangankan untuk menggapai hal itu, bermain musik, menonton acara musik, mendengarkan musik, dan segala hal yang berhubungan dengan musik, Miguel harus sembunyi-sembunyi. Loteng rumah adalah studio kecil Miguel mengenal karya besar dan perjalanan sang idola serta bereksplorasi dengan dunianya, musik.

Coco adalah film dengan tema keluarga. Premis film ini tentang sebuah ikatan dalam keluarga yang kuat, nilai-nilai dalam tradisi, serta penghormatan pada budaya leluhur. Di sisi lain, Coco juga memberikan tambahan pemahaman nilai tentang unsur budaya dan tradisi di Meksiko. Penonton diajak memahami serta mengenal perayaan Dia de los Muertos yang menjadi kepercayaan masyarakat Meksiko. Hal ini tentu relevan bagi kebudayaan Indonesia. Indonesia sendiri memiliki banyak kepercayaan pada relasi dunia kematian seperti suku Toraja dengan upacara ritual Rambu Solo, suku Jawa dengan sesaji leluhur (kirim doa leluhur), dan juga budaya etnis Tionghoa dengan festival Ceng Beng.

Dia de los Muertos adalah sebuah perayaan di Meksiko setiap awal November sebagai bentuk menghormati leluhur dan orang yang telah mati. Perayaan ini dipercaya menjadi reuni keluarga besar antara dua dunia, kehidupan dan kematian. Itu bukanlah momen untuk berduka, melainkan mengingat kembali anggota keluarga dan orangorang yang telah berpulang, menjaganya agar tetap dekat di hati. Begitulah Coco mengenalkan dan mengajari relasi dalam keluarga melalui budaya Latin, Meksiko.

\section{Pembahasan}

\section{Sederhana Namun Memikat}

Sebuah skenario bisa lebih dari sekadar komunikatif, maksudnya lebih dari sekadar bisa dimengerti dengan jelas. Lebih dari sekadar dimengerti, sebuah skenario bisa menularkan emosi, merangsang pembacanya untuk berpikir bagaikan suatu karya yang memang dibuat untuk dibaca, sebagai suatu karya tekstual. Ketika ia mampu mengharukan dan menggugah suatu kehendak pada pembacanya, maka dalam konteks pembicaraan ini ia tidak lagi sekedar komunikatif, tidak sekadar bisa dimengerti, melainkan telah menjadi skenario ekspresif, yakni skenario yang mengandung muatan-muatan literer, sehingga mampu menggerakkan emosi, pikiran, dan jiwa pembacanya (Ajidarma, 2000:62).

Seandainya Pixar adalah superhero layaknya tokoh fiksi dalam serial Marvel, maka kekuatan supernya pasti adalah kemampuan untuk membuat penonton empati pada seluruh naratif yang dibangun dalam film Coco. Skenario sebagai ujung tombak utama dalam strategi bertutur menjadi pokok perhatian dalam film Coco. Mengunci penonton menit demi menit dan mulai mempengarui emosi dan psikologi. Pemanfaatan ruang dan waktu imajinasi penonton dibangun dalam hubungan keluarga yang sederhana. Imajinasi tak terbatas penonton adalah kunci dalam karya besar Pixar.

Coco bukan sekedar mengambil kisah dan budaya dari Meksiko, tetapi Coco melukis kembali kebudayaan Meksiko dengan indah dan tetap menggugah rasa. Dari hal yang kasat mata seperti penamaan, logat, dan busana hingga yang tak nampak seperti hubungan keluarga. Orang-orang Latin dikenal punya kultur keluarga yang erat. Mereka mengenang dan mengingat masing-masing sanak saudara baik yang hidup maupun yang 
tiada. Rasa hormat dan sayang pada sosok mama atau ibu adalah sisi lain karakter orang Latin. Eratnya hubungan keluarga inilah yang dikemas dalam produk budaya pada film Coco. Adrian Molina dan Matthew Aldrich begitu cerdas dan peka dalam menggarap naskah film ini. Penempatan foto diawal scene menjadi unik sekaligus penggerak cerita, sebab foto punya banyak cerita di baliknya.

Coco adalah sebuah film dengan cerita yang kaya. Tema keluarga yang diusung menjadi pijakan kuat dalam menyampaikan gagasan. Co-Director film Coco yang juga salah satu penulis naskahnya, Adrian Molina bercerita bahwa Coco bukan sekadar film animasi yang menawarkan dunia imajinasi namun juga membawa pesan. Perjuangan Miguel dalam meraih mimpinya di antara sejumlah tekanan dari keluarga. "Tidak hanya itu, film ini juga akan menceritakan tentang pentingnya keluarga dan menghormati leluhur," ujar Adrian Molina melalui siaran pers-nya (https://www. bernas.id/62278-seperti-dugaan-coco-menangkategori-film-animasi-terbaik-oscar-2018.html. Di akses 26 Maret 2018, pukul 15.00 WIB).

Semuanya menekankan pentingnya cara bertutur yang dramatik, demi keterikatan penonton pada jalan cerita, dan sukses komersial film yang dibuat. Setiap perkembangan cerita selalu dihubungkan dengan reaksi psikologis yang akan terjadi pada penonton (Ajidarma, 2006:21).

Dalam tema besar ini, Coco menyuguhkan plot-plot yang membangun terjadinya konflik sebagai penghambat tokoh utama. Joseph M Boggs dalam bukunya The Art of Watching Film (1992), berpendapat bahwa tema dalam suatu film juga berguna sebagai pernyataan sifat manusia di mana film memberikan fokus pada tokoh universal atau representatif yang karakter tokohnya mewakili manusia secara umum, mereka digunakan sebagai tumpangan sinematik untuk memberikan ilustrasi mengenai beberapa kebenaran tentang sifat manusia yang selama ini telah ada dan berkembang dalam masyarakat sosial.

Persoalan dari ranah keluarga ini kemudian menjadi konflik yang ditarik keluar dan lebih luas. Miguel hanya gambaran kecil bagaimana struktur masyarakat telah membangun batasan-batasan hidupnya dan melegetimasinya. Pengakuan sosial menjadi hal yang penting dan terus dicari dewasa ini, dari pengakuan inilah keberadaan individu sebagai bagian sistem masyarakat memiliki peranan. Menonton Coco seolah melangkah ke dalam suatu kehidupan yang sedang berlangsung dan pengamat ditempatkan sebagai mata kamera obyektif. Budaya, backstory para tokoh, hingga pada persoalan lingkungan diceritakan secara ringan. Kilas balik terasa memperkuat dalam bertutur tiap scene. Film ini seperti dunia yang bahkan sudah bekerja sebelum penonton mengintipnya, inilah salah satu aspek terhebat dalam film Coco.

Sebuah cerita yang bagus adalah cerita yang dituntut mampu mengikat dan mengungkung perhatian penonton. Mulai dari kesatuan plot, masuk akal dan benar-benar terjadi, dan bagus. Dalam hal kebenaran, pembuat film dapat menciptakan kebenaran dengan bermacam-macam cara. Kebenaran yang secara lahiriah dapat dilihat, kebenaran batin dari sifat manusia, dan juga kemiripan artistik dari "kebenaran" dimana seoarang pembuat film membimbing penontonnya keluar dari dunia nyata lantas masuk ke dalam dunia imajiner cerita. Kompleksitas yang demikian rapi dan terjalin dalam plot tersusun rapi dalam film Coco.

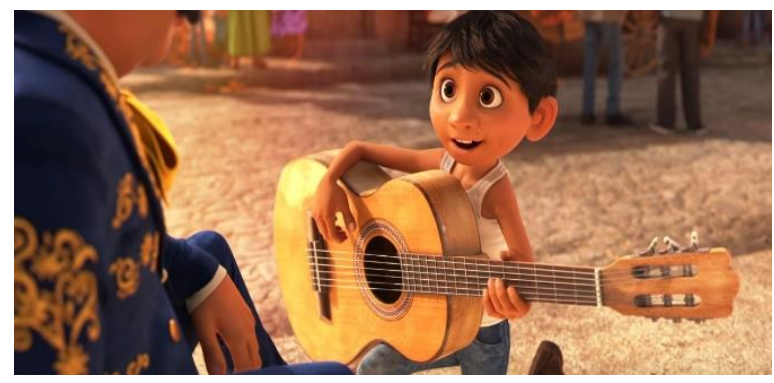

Gambar 2. Potongan adegan ketika Miguel meminjam gitar musisi jalanan di tengah kota (Sumber: Disney. Pixar's "Coco")

Meskipun tokoh utama film ini adalah Miguel dengan mimpinya sebagai musisi namun justru nenek Coco yang namanya dijadikan label bukan Migeul atau bahkan Ernesto De La Cruz. Tampaknya Pixar sejak dini ingin menunjukkan kepada penonton secara tersirat bahwa film ini bukan tentang perjuangan Miguel semata atau keindahan dunia mati namun sebuah relasi keluarga. Mama Coco adalah nenek buyut kesayangan tokoh utamanya, Miguel dan juga seluruh keluarga besar Abuelita. Lagu-lagu Ernesto De La Cruz dikenal dari Coco yang pada akhirnya kita semua tahu bahwa semua lagu yang dibawakan adalah ciptaan Hector. Coco memang bukan tokoh utama dalam film ini namun dia tokoh kunci bagaimana alur cerita bergerak.

Beberapa judul tertentu mungkin dimaksudkan untuk mengarahkan perhatian kita pada sebuah adegan kunci dalam sebuah film yang pantas untuk dikaji secara khusus, jika kita menyadari bahwa judul film itu dipetik dari adegan tersebut (Sani, 1992:75). 
Mengkaji tokoh Coco maka penonton akan mengerti serpihan-serpihan konflik yang disematkan dalam film ini. Dari foto yang ada di altar tanpa kepala kakek bunyut Miguel. Gitar yang sama dengan makam Ernesto, hingga lagu Remember Me. Pecahan puzzle semakin jelas ketika Miguel terjebak dalam dunia mati dan berjumpa Hector dengan kilas balik perjalanan hidupnya. Nenek Imelda yang juga ibu Coco pun hadir sebagai penguat dramatiknya. Lantas ketika semua telah menemukan titik terang, barulah puncak melankolis film ini nampak. Adegan Coco yang semakin lupa akan kenangan dan Miguel yang berusaha mengingatkan Hector padanya berujung sia-sia. Hanya petikan gitar dan lantunan Remember Me yang mampu mengoyak ingatan rapuh Coco kembali pada fase paling dikenangnya, Papa Hector. Dari sebuah laci, Coco memberikan potongan foto wajah Hector yang sejak film dimulai sesungguhnya adalah clue utama kemana film ini akan bergulir.

\section{A. Meramu Elemen Visual}

Hal lain yang menjadi senjata dalam film animasi Coco adalah visual. Tak dapat dipungkiri, bahwa selain memperoleh cerita yang bagus penonton juga ingin mendapatkan pengalam visual yang menggugah rasa. Maka dalam menikmati sebuah film tentu ada dua aspek besar yang membentuknya. Segi naratif dan segi sinematografi. Oleh karena unsur visual adalah alat dasar film dalam berkomunikasi, maka ia merupakan faktor yang sangat penting. Dalam urusan sinematografi, detildetil gambar pada Coco dikerjakan tidak dengan asal. Hal ini ditunjukan dengan shot landscape kota, jalanan, hingga pada shot-shot close up dalam menciptakan arti-arti simbolik. Semuanya dipikirkan dengan matang dan perhitungan. Gambar yang hidup dan seakan nyata. Bahkan saat masuk kedunia kematian dan perayaan dalam dua alam yang berbeda, Coco memberikan sentuhan yang berbeda baik. Kematian yang identik dengan sesuatu yang kelam justru divisualkan sebaliknya, disuguhkan dengan cara Pixar. Penampakan yang berwarna-warni meskipun tak mengurangi emosional dalam segi bertutur.

Georges Melies seorang pembuat film dari Prancis yang mengawali debutnya dengan film fantasi memiliki pandangan lain dalam pemanfaatan sinematografis sebuah film. Salah satunya, sudut pandang sinematogafi fantastik. Yakni sudut pandang yang meramu dan mengakali segala bahan menjadi fantasi, menajubkan. Di dalamnya termasuk segala siasat untuk menciptakan ilusi, seperti: penataan cahaya, trik foto, gerak kamera, warna, dan juga unsur pendukung dalam suatu mise en scene. Sebagai suatu seni baru, film memiliki kemampuan menciptakan ilusi atau fantasi (Sugiharto, 2013:318).

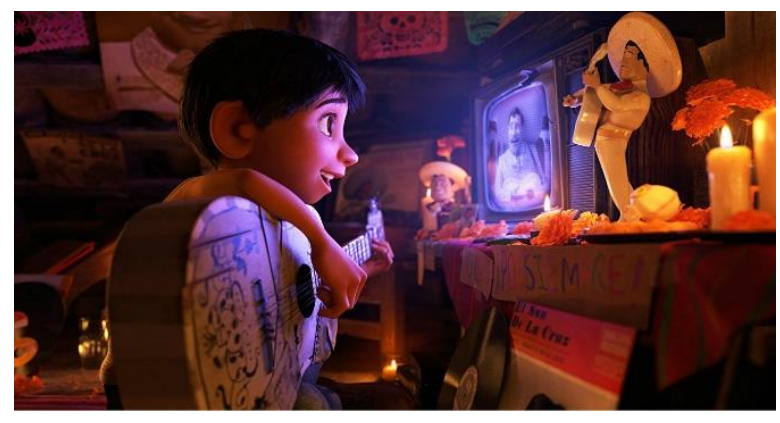

Gambar 3. Potongan adegan loteng tempat Miguel belajar musik dan bernyayi (Sumber: Disney.Pixar's "Coco")

Dalam hal ini, ada lima hal yang divisualkan dengan kuat pada film Coco dan mewarnai ceritanya. Lima elemen ini sangat mendukung dan mempengaruhi jalan cerita Coco serta Meksiko dengan Dia de los Muertos sebagai settingnya. Lima hal itu antara lain:

1. Papel Picado

Papel Picado adalah sebutan orang Meksiko untuk seni papercutting. Sebuah seni dari lembaran kertas yang dipotong menurut pola tertentu membentuk gambar dan dimaknai berbeda setiap kultur serta negara. Papel Picado merupakan salah satu karya seni tradisional Meksiko dipergunakan sebagai umbul-umbul atau hiasan di jalan-jalan dalam acara tertentu. Papel Picado atau seni papercutting sering dijadikan dekorasi pada saat perayaan hari orang mati.

Penggunaan Papel Picado pada film Coco justru ditempatkan dimenit pertama sebagai eksposisi keluarga Miguel serta persoalan yang nampak dari luar dalam keluarganya. Selain sebagai urutan silsilah keluarga sebetulnya diawal film dengan penggunaan Papel Picado penonton sudah dibawa secara perlahan dalam pembahasan tema keluarga serta Coco yang kehilangan sosok Ayahnya yang diakhir cerita diketahui bahwa Hector adalah ayah Coco yang tak lain kakek buyut Miguel.

2. Anjing Xolo

Dante, anjing jalanan yang mengikuti Migeul kemanapun dia melangkah. Bahkan saat Miguel diam-diam belajar musik, Dante adalah teman yang selalu mendengarkannya. Hal ini terlihat saat dalam percakapan, dimana Miguel telah memberi nama untuk anjing liar dan diperingatkan oleh neneknya (Abuelita). Dante pula yang mengikuti Miguel ke dunia kematian dan menyelamatkannya dari kekejaman Ernesto De La Cruz. 
Dante merupakan jenis anjing Xoloitzcuintli khas Meksiko yang tidak memiliki bulu. Nama Xoloitzcuintli berasal dari dua suku kata dalam bahasa Aztec, yaitu "xolotl" yang berarti dewa petir dan kematian, serta "itzcuintli" atau anjing. Menurut kepercayaan Aztec, anjing Xolo diciptakan oleh dewa sebagai penjaga yang hidup dan penuntun arwah yang hendak menuju dunia bawah lewat Mictlan (http:/hiburan. metrotvnews.com/film/GbmJB39k-lima-elemenvisual-meksiko-dalam-film-coco. Diakses 20 Maret 2018, pukul 08.00 WIB).

3. Ofrendas

Ofreda atau persembahan seperti sesaji dari sekumpulan benda, makanan, dan juga foto leluhur yang diletakkan di altar ritual selama perayaan Dia de los Muertos. Foto leluhur dipasang secara tersusun dari paling buyut hingga paling muda. Kenangan tentang mereka diceritakan secara turun temurun oleh anggota keluarga yang lebih tua, dalam kisah Coco nenek Abuelita memiliki adil besar dalam susunan cerita.

Coco menunjukkan Ofreda sama seperti seni papercutting, di awal film. Tokoh Miguel dikenalkan kepada penonton saat ia memandangi Ofreda di altar rumahnya. Ofreda menjadi elemen penting cerita karena persembahan ini berkaitan dengan kenangan akan sosok yang telah mati. Kenangan dan relasi keluarga inilah yang akan menjadi alur dan tema besar Coco.

4. Bunga Marigold

Meksiko punya jenis bunga marigold berwarna jingga menyala. Nama ilmiahnya Tagetes erecta atau orang Meksiko sering menyebutnya flor de muertos (bunga orang mati). Dalam era Aztec, bunga berwarna jingga terang dimaknai sebagai simbol dari matahari (http://hiburan.metrotvnews.com/film. Diakses 20 Maret 2018, pukul 08.00 WIB).

Dalam film Coco, bunga marigold muncul di sepanjang jalan menuju tempat pemakaman dari rumah-rumah penduduk. Marigold juga ada saat Miguel memetik gitar miliki Ernesto, jembatan penghubung dunia kematian juga merupakan susunan Marigold yang tertumpuk menyala-nyala. Kelopak bunga ini pula yang membawa Miguel kembali kedunia orang hidup.

5. Calaveras

Jika Papel Picado adalah seni papercutting ala Meksiko, maka calaveras adalah seni lukis mereka untuk menggambrakan tengkorak leluhurnya. Gambar tengkorak ini menjadi simbol perayaan Dia de los Muertos dan muncul dalam berbagai hiasan, kostum, make-up, hingga bentuk makanan.
Desain visual karakter arwah dunia orang mati dalam film Coco mengadaptasi ikon khas tengkorak ini dengan memberikan sentuhan pada mata, susunan tulang, dan baju yang dikenakan supaya dapat memberikan penekanan emosi serta strata sosial meskipun mereka sudah menjadi arwah.

Kelima elemen visual diatas adalah hasil yang ditemukan dalam riset dan diterapkan pada film Coco baik sebagai identitas maupun simbolik. Film mendekontruksi ulang pengalaman yang didapat dan memang terjadi di budaya Meksiko. Dari sebuah realitas objektif diubah menjadi gerak akal subjektif. Aspek rekayasa ulang pada film Coco bukan sekedar proses imitasi atau jiplakan semata, melainkan membentuk ulang kenyataan yang kreatif.

Melalui film sebagai metabahasa, identitas subjek dan cara film memaknai peristiwa dibentuk agar menciptakan hasrat baru dan cara pandang baru dalam suatu keadaan. Melalui elemen visual, Coco mendobrak identik dunia kematian yang suram dan cenderung dengan kontras tajam, warna gelap, atau permainan cahaya yang memiliki perbandingan tinggi (low key). Hal inilah yang membuat visual Coco merupakan bentuk subversi terhadap tendesi naratif dominan dalam masyarakat. Pada titik ini, film berfungsi sebagai kritik atas ideologi yang dominan. Konsekuensinya dari siasat itu, karakterkarakter dalam film itu tak bisa diidentifikasi secara pasti dan final (Sugiharto, 2013: 324).

\section{B. Kekuatan Musik Dalam Film}

Musik adalah sebuah elemen penting dalam sinema, sebuah alunan nada-nada dinamis mampu mempengaruhi emosional dalam film. Musik adalah bahasa yang universal dan paling mudah dimengerti oleh setiap awam, maka tak heran jika dalam musik tak luput suatu pesan khusus yang disematkan. Baik itu gagasan ide maupun perspektif lain. Seiring berkembangnya teknologi film, maka musik memiliki peranan besar didalamnya. Musik menjadi bagian primer bagi sebuah sinema. Perlahan musik mulai berevolusi menjadi unsur pembangun naratif. Begitu pula pada film Coco yang berkisah tentang musik dan relasi dalam keluarga.

Pada saat orang dapat menyajikan suara realistik dengan menambahkan dialog dan efek suara yang direkam, musik sudah membuktikan bahwa ia adalah pengiring yang sangat efektif untuk emosi dan irama yang dipadukan dengan gambar yang dibentuk di atas layar putih (Sani, 1992:159). 
Musik dan lagu dalam sebuah sinema terbukti memiliki peranan yang saling membutuhkan dan mengisi. Tak terkecuali dalam film "Coco". Lagu Remember Me dijadikan salah satu original soundtrack yang terbukti menyentuh rasa penonton dan mendapat apresiasi pada perhelatan Academy Award 2018. Remember Me ditulis oleh Kristen Anderson-Lopez dan Robert Lopez. Scoring musik dilakukan oleh Michael Giacchino.

Di samping itu, Remember Me juga dihadirkan dalam empat versi yang memiliki unsur harmoni berbeda dengan tujuan berbeda pula. Versi pertama dinyanyikan oleh Ernesto de la Cruz, penyanyi legendaris yang di idolakan oleh tokoh utama, Miguel. Irama pada musik ini menghentak keras, enerjik khas musik latin. Ada dominasi permainan gitar dan terompet sama persis dengan visualisasi tokoh Ernesto. Memiliki kekuasaan, seorang bintang, legenda, dan juga penggerak musik di Meksiko dalam film Coco. Versi kedua dinyanyikan oleh Hector yang tak lain adalah kakek Migeul. Pada versi ini, Remember Me jauh dari kesan keras namun justru melankolis dengan iringan gitar akustik. Nuansa serupa ditunjukan dalam versi ketiga yang dibawakan oleh Miguel saat film hampir selesai dengan nenek Coco yang duduk termenung.

Di sinilah kekuatan dan romantis dari Remember $M e$ begitu mengikat pendengar dan penonton. Versi keempat nerupakan soundtrack resmi yang muncul pada akhir film. Irama terkesan lebih pop serta modern ketimbang lainnya. Kesan riang, gembira, dan sukacita tampak dalam harmonisasinya. Hal ini dikuatkan dengan visual di mana Coco bertemu kedua orang tuanya pada dunia kematian dan Miguel kini telah bebas memainkan musik dirumahnya.

Musik, sebagai hiburan harus berdiri sendiri, tetapi sebagai musik latar belakang film tidak boleh menarik perhatian sebagai musik sendiri. Musik itu harus membantu dalam membimbing keadaan jiwa (mood) penonton, tetapi tidak boleh sedemikian kuat, sehingga menggangu perhatian untuk gambarannya. Musik harus dipergunakan sebagai introduksi, untuk membimbing, dan menandai emosional cerita (Livingstone, 1969: 127).

Miguel yang lahir dan besar di keluarga pengrajin sepatu bernama Rivera (Meksiko) memiliki impian lain, musisi. Rivera adalah perusahan sepatu yang produktif, konservatif, tradisional, dan legenda karena diteruskan turun-temurun. Bila masyarakat Meksiko memiliki ikatan erat pada seni musik maka tidak pada keluarga besar Rivera. Musik adalah hal kelam, kutukan, bencana, dan hal yang harus dijauhi. Nada, ketukan, alat musik terutama gitar sangat mereka membenci. Kebencian pada musik yang sangat mengakar ini membuat keluarga Rivera memisahkan diri dari kegiatan sosial bertema musik.

Musik, pada adegan pembuka adalah sesuatu yang sangat dielukan oleh keluarga Rivera, tapi pada akhirnya musik ini disalahartikan. Karena salah kaprah, musik membawa mereka kepada hasrat kebebasan individu yang menghasilkan sebuah pengkhianatan dalam struktur keluarga. Pengingkaran ini dilakukan oleh Miguel dengan memuja musik sebagai jalan hidupnya. Mengumpulkan artefak idolanya, bermain gitar butut kesayangannya, dan berulang-ulang menonton video musik Ernesto.

Musik pun jadi pemantik utama untuk memperjuangkan sebuah revolusi dalam skala kecil, diri Miguel. Tanpa disadari, musik turut berperan vital dalam menyatukan potongan-potongan tangga dramatik. Film ini memiliki tipe lagu-lagu melankolis tentang kehilangan yang selalu efektif menyayat hati, terutama pada lagu Remember $M e$. Dari lagu inilah kebenaran mulai terungkap perlahan-lahan hingga pada klimaks dan penyelesaian.

Aliran pikiran modern beranggapan, bahwa musik boleh, pada kesempatan-kesempatan yang tepat, bukan sekedar menuntut perhatian kita secara sadar, tapi ia bahkan boleh menguasai gambar, selama ia pada dasarnya tetap merupakan satu perpaduan dengan unsur-unsur visual, dramatik, dan irama sebuah film sebagai keseluruhan (Sani, 1992: 161).

Musik di dalam film digunakan untuk menambahkan dramatisasi dalam sebuah cerita, karena dengan menggunakan musik, pembuat film dapat mengendalikan emosi penonton dalam mengikuti cerita. Musik dalam film dapat digunakan untuk menaikan atau menurunkan emosi penonton, sesuai dengan kebutuhan cerita. Kehadiran musik digunakan untuk merangsang dan mengarahkan perasaan sesuai dengan apa yang dilihat secara visual : senang, sedih, takut, tertekan, dan lain-lain. Sumber dramatis dari musik dalam sebuah adegan dapat bersifat berkaitan dengan adegan, atau fungsional dan realitas.

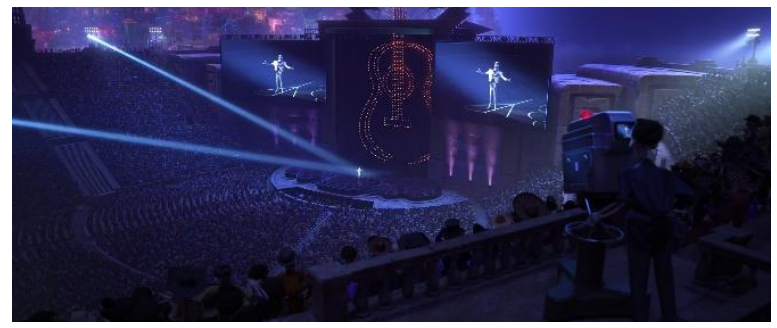

Gambar 4. Potongan adegan konser Ernesto di dunia kematian (Sumber: Disney.Pixar's "Coco") 
Musik fungsional, yaitu musik yang digunakan untuk menambahkan dramatisasi didalam film, yang berasal dari luar ruang adegan cerita, biasa disebut musik ilustrasi. Musik yang didengar oleh penonton tidak berasal dari sumber suara dalam adegan maupun didengar oleh karakter dalam adegan. Sedangkan musik realitas, yaitu musik yang berasal dari dalam ruang adegan cerita. Fungsinya untuk menciptakan kesan realita, contohnya musik ketika tokoh Miguel menyanyi dipanggung dalam dunia kematian dengan lagu Un Poco Loco. Dalam hal ini, musik yang didengar oleh penonton juga didengar oleh karakter dalam film.

Seringkali musik juga berfungsi melebihi peranannya sebagai sesuatu yang bersifat saling mengisi dan melayani serta menduduki fungsi "bercerita" yang penting. Hal ini khusus kita temui pada hal-hal dimana keadaan fikiran seorang tokoh mengalami perubahan cepat dan radikal yang tidak dapat diutarakan melalui gambar dan kata-kata dengan cara yang memadai (Sani, 1992: 165).

Salah satu contoh dalam film Coco yang menggunakan peranan musik dan lagu dengan baik selain pada adegan ending adalah saat Miguel dan Hector meminjam gitar pada temannya di tepi pantai. Saat itulah Miguel baru tahu bahwa kemampuan Hector dalam memainkan alat musik dan bernyanyi. Lagu yang dibawakanpun merupakan ucapan terimakasih sekaligus kata perpisahan untuk temannya. Sebuah kematian yang sebenarnya, tanpa kenangan dan dikenang. Seiring bergulirnya waktu, musik bukan lagi latar dalam sinema untuk mengisi ruang kosong, musik bukan lagi berbicara aspek bunyi dalam bentuk seni pertunjukan semata. Lebih dari itu, musik bahkan mengandung pesan kuat yang mampu membangkitkan jiwa dan membentuk perspektif baru dalam satu kesatuan sinema.

Terkadang musik juga membentuk kombinasikombinasi yang unik dengan citra visual untuk menciptakan tataran tambahan yang lebih hidup, seperti beberapa potongan adegan festival musik di dunia kematian atau juga pada malam puncak Ernesto tampil di depan jutaan penggemarnya. Tingkat atau lapisan ironis yang tinggi sekali dapat dicapai dengan mempergunakan musik yang mengingatkan pada suatu rasa yang bertolak belakang dengan rasa yang dikesankan oleh peristiwa yang nampak (adegan Ernesto duet dengan Imelda dan Hector mengiringi dengan gitar akustik). Lapisan musik dalam visual ini bukan disuguhkan sebagai pemanis semata namun adalah kisah panjang yang mengikutinya. Bagaimana awal mula karis Ernesto, bagaimana kehidupan Hector dan Imelda jauh sebelum ia meninggalkan Coco ketika kecil hingga pada rasa membenci yang tertanam dalam hati Imelda. Visual dan musik saling tumpang tindih dalam melakukan peranannya.

\section{Kematian Tak Melulu Menyeramkan}

Secara mudah setting adalah waktu dan tempat di mana cerita dalam film berlangsung. Semakin detail penggambaran setting maka semakin mudah penonton memahami latar belakang ceritanya. Dalam memilih setting ada empat faktor yang perlu dipertimbangkan menurut Boggs (1992) dalam The Art of Watching Film, yaitu : faktor temporal, faktor sosial ekonomi yang berlaku, faktor adat istiadat, dan faktor geografik. Keempat faktor ini mempunyai efek yang penting terhadap konflik dan karakter tokohnya. Begitu pula yang dilakukan oleh Pixar ketika memilih Meksiko dengan Dia de los Muertos sebagai setting penting dalam film Coco.

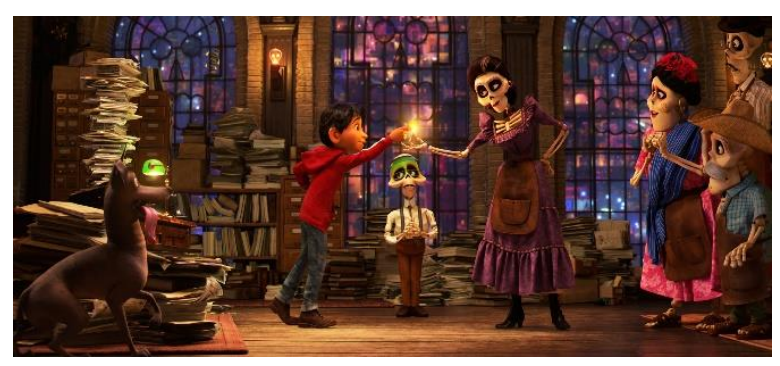

Gambar 5. Potongan adegan saat Miguel bertemu dengan keluarga besarnya di dunia kematian (Sumber: Disney. Pixar's "Coco")

Selain memiliki cerita yang kaya, Coco punya tokoh yang bisa dengan mudah di apresiasi sebagai figur masyarakat sendiri. Film ini bicara tentang sebuah keabadian diri lewat seni, dengan karya, dengan menciptakan sesuatu, dan dimiliki oleh cinta maka orang akan terus membicarakan sekalipun telah mati. Adegan yang menunjukan orang Meksiko berziarah kepemakaman pada film Coco adalah salah satu hasil riset yang diimplementasikan dengan baik. Budaya ziarah pada saat perayaan Dia de los Muertos dipercaya memberi harapan agar arwah sanak saudara yang telah mati bisa berkunjung kembali ke dunia orang hidup.

Dia de los Muertos adalah hari raya di Meksiko untuk mengenang orang yang sudah tiada. Pada hari itu (tepatnya tanggal 1 dan 2 November) dipercaya leluhur yang sudah meninggal akan mendatangi rumah kerabat yang masih hidup, selama mereka masih diingat. Hal tersebut dijadikan stake dalam film ini, sebuah tradisi yang telah mengakar di sosial masyarakat Meksiko. Masyarakat Meksiko meyakini, orang yang sudah mati tidak akan benar-benar pergi, mereka tetap ada secara rohani, sampai tidak ada lagi yang mengenang mereka. 
Kenangan yang membuat mereka seakan masih hidup dan tinggal dalam hati melalui cinta. Kegiatan dalam perayaan Dia de Muertos antara lain membersihkan makam leluhur dan menghiasinya dengan berbagai ofrenda (persembahan), dan tentu saja seluruh elemen keluarga menghiasi rumah mereka dengan membuat altar. Detaildetail benda-benda seperti sesaji, foto, makanan kesukaan yang ditata rapi disetiap meja rumah hingga kelopak bunga marigold dan arwah binatang sebagai binatang penuntun di alam baka.

Setting pada film Coco adalah pantulan karakter orang Meksiko yang ingin dibicarakan oleh pembuatnya. Orang Meksiko divisualkan memiliki relasi yang kuat dalam nilai-nilai keluarga. Keluarga sebagai pusat dari struktural sosial, maka menghormati keluarga adalah hal yang penting dan terutama. Lingkungan dimana Miguel hidup dapat memberikan gambaran pemahaman karakternya kepada penonton, terutama dalam hubungan dengan efek yang dimiliki manusia terhadap lingkungan yang dia kuasai.

Dengan memotret detail-detail tertentu yang terdapat dalam sebuah setting, sutradara dapat menekankan aspek kasar dan jorok atau ciri-ciri romantis dan ideal dari sebuah lingkungan (Sani, 1992:195).

Pada dunia kematian yang digambarkan dalam film Coco penonton seakan melihat bahwa sosial ekonomi seakan mengikuti kemana manusia itu pergi. Misalnya, hanya dengan pemilihan busana saja penonton dengan mudah mengidentifikasi golongan manusia dalam film Coco. Pemusik selalu dengan setelan jas dan alat musiknya, orang biasa dengan busana sehari-harinya, publik figur dengan busana mewah dan warna megah yang disandangnya, sedangkan kaum marginal dan terpinggir disematkan busana yang terkoyak. Belum lagi berbicara soal tempat tinggal yang memiliki kesenjangan cukup jelas antara si kaya dan si miskin. Untuk bisa menikmati dan melihat pentas seorang superstar masyarakat harus berlomba agar mendapatkan tiket gratis berjumpa dengannya.

Tingkat sosial dan ekonomi yang menjadi pusat perhatian dalam dunia kematian seakan mengingatkan kita bahwa betapa manusia telah terkotak-kotak dalam konteks yang paling nyata, harta dan kekuasan. Untuk mampu menuju lingkaran yang terpandang maka masyarakat harus siap memasuki sebuah arena besar dengan segala bentuk permainan dan aturan yang telah ada. Sosial ekonomi layaknya sebuah permainan yang dengan mudah bisa dibolak-balik dalam film Coco. Tergantung bagaimana si kaya dalam hal ini
Ernesto ingin menjupai dan memilih siapa melalui regulasi yang ia mainkan.

\section{Simpulan}

Coco adalah film yang mengajarkan arti kematian dengan cara yang menyenangkan sekaligus membangun arti relasi keluarga yang sederhana namun kokoh. Dalam kasus ini, Coco mengajarkan kita tentang sudut pandang moralitas, sosial, dan pedoman hidup. Hal ini tentu membantu kita memperoleh pengertian yang lebih jelas tentang aspek kehidupan, fitrah manusia, pengalaman hidup, dan kondisi manusia. Coco memiliki kekuatan gagasan yang membicarakan hal yang kasat mata hingga tak nampak oleh mata, relasi dan cinta. Sosial, kultural, hingga intelektual disuguhkan tanpa menggurui sedikitpun pada penonton. Namun memberi dorongan kepada kita bagaimana memposisikan keluarga dalam hidup. Baik melalui naratif, penokohan, sinematografi, tata cahaya, setting, suara dan editing semuanya memiliki sumbangan yang efektif dalam mengomunikasikan pesan pokok film ini.

Kebenaran tetaplah kebenaran, sejauh mana Hector menyimpannya maka akan ada waktu yang tepat bagi Imelda dan juga Miguel mengetahui hal itu. Maka tak heran jika pada akhir film, rumah kediaman Miguel menjadi perpustakaan bagi artefak Hector. Perjalanan musisi dan tulisan lagunya terpampang di sana. Miguel memainkan gitar dengan riang dan sukacita ditengah keluarga besarnya (dunia nyata dan dunia orang mati, tampak pula arwah Hector dan mama Coco). Film Coco memiliki unsur kuat sekaligus efektif untuk masuk keruang bawah sadar penonton dalam menyampaikan pesan untuk mencintai keluarga kita masing-masing. Sebuah pesan universal yang disematkan dalam hubungan yang relevan saat ini.

\section{Daftar Pustaka}

Ajidarma, Seno Gumira. 2000, Layar Kata, Yayasan Bentang Budaya, Yogyakarta.

Boggs, M Joseph. 1992, The Art of Watching Film atau Cara Menilai Sebuah Film, terjemahan Drs. Asrul Sani, Yayasan Citra, Jakarta.

Livingstone, Don. 1969, Film and The Director, Capricorn Book, New York.

Sugiharto, Bambang. 2013, Untuk Apa Seni?, Matahari, Bandung.

https://www.bernas.id/62278-seperti-dugaan-cocomenang-kategori-film-animasi-terbaik-oscar2018.

http://www.cnnindonesia.com/hiburan/2017120410 3118-220-259904/coco masih dominasi puncak box office.

http:/hiburan.metrotvnews.com/film/GbmJB39k lima elemen visual meksiko dalam film coco. 